OPEN ACCESS

Edited by:

Gary Cheung,

The University of Auckland,

New Zealand

Reviewed by:

Yanick Charette,

Laval University, Canada

Bryce Jenkins,

Carleton University, Canada

*Correspondence:

Ron Hoffman

ronhoffman@nipissingu.ca

Specialty section:

This article was submitted to

Public Mental Health,

a section of the journal

Frontiers in Psychiatry

Received: 16 June 2021 Accepted: 20 September 2021

Published: 18 October 2021

Citation:

Hoffman R, Harman J, Kinsell H and

Brown G (2021) Costs and Savings Associated With the Police Use of the interRAl Brief Mental Health Screener.

Front. Psychiatry 12:726469.

doi: 10.3389/fpsyt.2021.726469

\section{Costs and Savings Associated With the Police Use of the interRAI Brief Mental Health Screener}

\author{
Ron Hoffman ${ }^{1 *}$, Jeffrey Harman ${ }^{2}$, Heidi Kinsell ${ }^{2,3}$ and Gregory Brown ${ }^{1}$ \\ ${ }^{1}$ School of Criminology and Criminal Justice, Nipissing University, North Bay, ON, Canada, ${ }^{2}$ Department of Behavioral \\ Sciences and Social Medicine, Florida State University College of Medicine, Tallahassee, FL, United States, ${ }^{3}$ Department of \\ Geriatrics, Florida State University College of Medicine, Tallahassee, FL, United States
}

Background: The police response to calls for service identified as being related to mental health continues to be highly controversial. Strategies to improve the police response include Crisis Intervention Team (CIT) training and various forms of co-response models neither of which have been subjected to comprehensive evaluations, particularly as to cost-efficiency. A new approach is the use of the interRAl Brief Mental Health Screener to enhance police officer ability to identify persons with serious mental disorders. The purpose of the current study is to evaluate the costs and cost efficiency of the police response to mental health calls using the interRAl Brief Mental Health Screener.

Method: Secondary data was analyzed from the use of the screener from 2018 to 2020 by police officers in a mid-sized Canadian city. Changes were measured in the overall number of interactions police officers had with persons with mental health disorders, the number of incidents where police officers referred the person to hospital, and the time officers remained in the emergency department.

Results: A total of 6,727 assessments were completed with involuntary referrals decreasing by $30 \%$, and voluntary referrals by $34 \%$. The overall time police officers were involved in involuntary referrals decreased from $123 \mathrm{~min}$ in 2018 to $113 \mathrm{~min}$ in 2020. The average emergency department wait time for voluntary referrals dropped from $41 \mathrm{~min}$ in 2018 to $27 \mathrm{~min}$ in 2020, while involuntary referrals decreased from $61 \mathrm{~min}$ in 2018 to 42 min in 2020. Each averted involuntary referral to the emergency department resulted in a savings of $\$ 81$, on average during the study period.

Conclusion: An analysis of the costs and costs savings associated with the use of the screener demonstrate that it is a worthwhile investment for police services. An additional benefit is its ability to collect mental health statistics that may be useful to police leaders to justify budgets. Future studies should attempt to devise some method of collecting pre-implementation data that would reveal the true costs and cost-efficiency of using the BMHS, which have been shown to be significant in the current study however, undoubtedly are under-estimated.

Keywords: costs, resources, policing, mental, disorder 


\section{INTRODUCTION}

During the course of their duties, police officers interact with persons exhibiting a broad range of behaviors related to mental disorder from indicators of disordered thought alone to behaviors that may pose a risk of harm to themselves or to others. Public attention is often drawn to negative incidents such as those involving excessive use of force, and on the question of whether police officers receive sufficient training on mental health issues (1-8). Police officers themselves often feel ill-prepared for calls for service identified as being related to mental health $(6,7)$. Additionally, police leaders have voiced concern over how such calls are particularly resource-intensive and costly due to the number of officers involved, the overall length of the calls and the time and resources involved in transporting the person to hospital (9-14). Although considerable time, effort and public funds have been directed toward implementing new approaches to improve the overall police response to persons with serious mental disorders (PSMD), evaluating their overall effectiveness and cost-effectiveness has been problematic $(15,16)$.

Two major new approaches designed to help police better respond to PSMD involve providing additional training for frontline police officers and implementing co-responder models comprised of police officers and mental health professionals (15). One of the most popular models to enhance police training is the Crisis Intervention Team (CIT), where police officers volunteer to receive additional training on mental health issues $(17,18)$. The Co-Response Team (CRT) model, referred to as the Mobile Crisis Intervention Team (MCIT) in United States, Canada and Australia and "street triage" in the United Kingdom consists of a police officer paired with a mental health professional to respond to calls for service identified as being related to mental health (19-23). While the CIT model continues to be popular in the United States, Canada and Australia $(17,19)$, CRTs are currently the most prevalent model in the United Kingdom (22).

A third approach to improving the police response to PSMD is the Hub/Situation Table model based on the work of Scotland's Violence Reduction Unit and the Hub model introduced in Saskatchewan, Canada (15). Known as the Community Safety and Well-being movement, proponents of the model believe that calls for service such as those involving mental health, homelessness and substance abuse are largely social issues as opposed to criminal matters and therefore should not be the sole responsibility of police organizations. Instead, the responsibility should be shared with other community organizations that are better equipped to respond. The "Situation Tables" is where representatives of various community agencies meet to discuss the most appropriate intervention for person(s) identified as being at elevated risk (24). This sharing of responsibility would should therefore lead to better outcomes for those experiencing the problems while at the same time easing the demand on police and police resources (24-27). The Hub/Situation Table model continues to expand across Canada where over 100 communities have adopted it (15).

Although these models represent innovative attempts to improve the police response to PSMD, few formal studies exist that have evaluated either their effectiveness or cost effectiveness
$(15,22)$. For example, the goals of CIT are to divert PSMDs away from the criminal justice system, enhance collaboration between police and community organizations, provide accessible mental health services and improve officer and client safety (15). Although the model has had some positive results such as improved officer attitudes and confidence in de-escalating encounters, there is controversy over whether the initial goal of enhancing officer and client safety has been achieved $(17,18,28)$. The few studies examining the cost effectiveness of the CIT model suggest modest savings primarily through the reduction in the use of police custody and the number of persons taken to hospital (or place of safety) by police officers (28-30). Similarly, the few studies examining the cost effectiveness of CRT models suggest that police organizations have realized some savings primarily through the reduced time spent on calls and time spent waiting in hospitals (31-35). A meta-analytic study suggests that the CRT model produces a stronger overall impact than crisis intervention training alone however the authors of the study recommend more research is required $(36,37)$. As to the Hub/Situation Table model, although it continues to expand and mental health cases represent a large proportion of the cases, there are currently no independent, peer-reviewed studies to support its effectiveness or whether its use has resulted in lower costs to police agencies (15).

A more recent attempt at improving the response to PSMD is the interRAI Brief Mental Health Screener (BMHS), an evidence-based instrument used to help police officers identify serious mental health issues according to behaviors indicative of disordered thought and risk of harm to self or others as opposed to symptoms or diagnoses (38-40). Software built around the BMHS enables officers to complete the assessment on their cell phones and to measure, with a series of algorithms, the capacity of the person to care for themselves, and the level of risk of harm they pose to themselves or others (41) which is consistent with police apprehension authorities. For example, in Canada mental health legislation authorizes police officers to take apparently mentally disordered individuals into custody without prior judicial authorization where there is a fear for the life or safety of the person, or a fear they are a risk to cause harm to others (42).

Though no evaluative studies exist, the BMHS has a distinct advantage over other models in that in addition to its potential to improve officers' ability to recognize indicators of serious mental disorder, it can track calls for service identified as being related to mental health. A major impediment to evaluating the effectiveness and cost-effectiveness of the various models designed to improve the police response is the fact that police services typically do not collect data related to non-crime related calls for service such as those involving mental health, homelessness and substance abuse. From a police organization perspective, the ability to monitor police responses to PSMD in real time, and to track the number of officers and time involved in the call supports deployment and efficient use of resources and helps to estimate costs. Thus, the BMHS has the additional capability of providing a financial basis upon which to evaluate the police vs. alternative, diversionary responses, and the most efficient use of resources. 
The growing budgetary constraints on police services, the mounting resource costs related to police responses to PSMD is a serious concern, and the cost-effectiveness of CRT, CIT, and Hub/Situation Table models of police response suggest little or no improvement or reduction in use of police resources. The current study represents one of the few research-based efforts to describe and evaluate the police response and use of resources related to calls for service that involve PSMD, making use of data collected with the BMHS in one mid-size police service in Canada.

\section{MATERIALS AND METHODS}

\section{Setting}

The setting for the study was Guelph, a mid-sized city in southwestern Ontario, Canada located 40 miles (65 kms) southwest of Toronto, Canada's most populous city. With a population of roughly 160,000 , the city is served by one acute care hospital, one resident long term care hospital for complex medical, and rehabilitation services and one center for specialized psychiatric and addiction services. The study used data collected through the use of the BMHS by police officers of the Guelph Police Service, the 14th largest municipal police service in Ontario with 323 members. The site of the study was specifically chosen because, as one of the original pilot sites for the BMHS, its officers have had extensive experience using the instrument and there were several years of data that could be analyzed.

\section{Data Collection Instrument}

The BMHS is a short, 23-item, evidence-informed mental health screening assessment instrument currently used by over 40 police services in Canada and the USA (29). Developed through an international effort, the BMHS is used to help police officers identify persons with the greatest probability of falling into a high risk category based on indicators of risk of harm and disordered thought. A primary source of items on the BMHS is the RAI$\mathrm{MH}$, the mental health assessment system currently used across the province of Ontario whenever a patient is admitted into psychiatric care. The BMHS standardizes observations made by police officers and acts as a framework to enable officers to better articulate the grounds to believe a person has a serious mental disorder. Given the terminology used on the form is consistent with the RAI-MH, the language itself acts as common currency between the systems promoting better integration of systems and services.

Guelph city police officers received initial training on how to complete the BMHS, followed by additional training on how to use the accompanying software. They were instructed to complete the assessment on any member of the public who in the course of their duties, they had reason to believe had a mental health disorder. A software system (29) was built around the BMHS enabling police officers to digitally complete the BMHS assessment on a terminal located in their patrol cars at the scene of the incident. The software also calculates three clinically validated algorithms embedded in the BMHS for risk of harm to others, harm to self, and self-care (the criteria for police apprehension). Risk scores are tracked over subsequent interactions with police officers providing objective clinical feedback to help police officers decide on the most appropriate course of action. The risk scores do not dictate action but rather support a police officer's decision and can be used to justify a police apprehension when communicating with hospital staff. After completing the assessment, the police officer wirelessly transmits a summary of observations made at the scene of the incident to predetermined destinations which could include a hospital and any designated community mental health agencies. In this way, if the decision is made to transport the person to the $\mathrm{ED}$, the hospital receives an early notification of incoming patients. If the assessment is sent to community agencies, it provides the information and consent (captured by the officer on scene) to initiate a follow up and provide counseling or support services if deemed appropriate.

\section{Data}

The software allows for digitized records of assessments to be securely stored in a databased at the Guelph police station and according to a research agreement with interRAI, all users of the BMHS must agree to forward de-identified data to the interRAI Canada data repository at the University of Waterloo where the investigators had access.

\section{Analysis}

The purpose of this analysis was to calculate cost savings over time that result from reductions in $\mathrm{ED}$ visits after implementation of the BMHS. To do this, using data collected through the BMHS, the total time of calls in minutes is compared between calls that resulted in an involuntary transport to the ED and the total time of calls that did not result in a transport to the ED. Next, the cost of the additional time associated with involuntary transports to the ED is calculated by using the hourly cost of police time (based on wages and benefits $=\$ 54 / \mathrm{h}$ ) and multiplying that cost by the additional number of minutes and the number of police officers that were involved with the call. For example, if there were two officers involved with the call and the involuntary trip to the ED added an extra hour to the call, the additional cost would be $\$ 108(1 \mathrm{~h} \times 2$ officers $\times \$ 54)$. This calculation is done for all 3 years combined (2018-2020). The total wait time in the ED is also calculated for each individual year to assess whether implementation of the BMHS reduces ED wait times from year to year.

Next, the proportion of all mental health related calls that resulted in (1) an involuntary transport to the ED; (2) a voluntary transport to the ED; and (3) no transport to the ED is calculated. As with the cost analysis, this calculation is done for all 3 years combined as well as for each of the 3 years after implementation of the BMHS. Additionally, the percent change in the proportion of mental health calls with each of these three outcomes from 2018 to 2020 is calculated.

\section{RESULTS}

Typical of the majority of police services, data collected by the service is almost exclusively crime-related which is used as a basis for estimating police budgets. Police services therefore, generally do not collect data specific to non-crime related incidents and 
TABLE 1 | ED referrals compared to no ED referrals by year.

\begin{tabular}{|c|c|c|c|c|c|}
\hline \multirow[t]{2}{*}{ Action } & 2018 & 2019 & 2020 & Total 2018-2020 & $\%$ Change 2018-2020 \\
\hline & $N(\%)$ & $N(\%)$ & $N(\%)$ & $N(\%)$ & \\
\hline ED referrals & $481(25.4)$ & 468 (19.4) & 331 (13.6) & $1,280(19.0)$ & $-31.2 \%$ \\
\hline No ED referrals & 1,412 (74.6) & 1,941 (80.6) & 2,094 (86.4) & $5,447(81.0)$ & $48.3 \%$ \\
\hline Total calls & $1,893(100)$ & 2,409 (100) & 2,425 (100) & $6,727(100)$ & $28.1 \%$ \\
\hline
\end{tabular}

TABLE 2 | Involuntary ED referrals compared to Voluntary referrals by year.

\begin{tabular}{lcccc}
\hline ED referrals & $\mathbf{2 0 1 8}$ & $\mathbf{2 0 1 9}$ & $\mathbf{2 0 2 0}$ & $\begin{array}{c}\text { \% Change } \\
\text { over time } \\
\mathbf{2 0 1 8 - 2 0 2 0}\end{array}$ \\
\hline Involuntary & $\mathbf{N ~ ( \% )}$ & $\mathbf{N ~ ( \% )}$ & $\mathbf{N ~ ( \% )}$ & $-30.1 \%$ \\
Voluntary & 326 & 314 & 228 & \\
Total & 67.8 & 67.1 & 68.9 & $-33.5 \%$ \\
& 155 & 154 & 103 & $-31.2 \%$ \\
& 32.2 & 32.9 & 31.1 & \\
\hline
\end{tabular}

in particular, calls for service identified as being related to mental health. References to mental health calls will appear in a police database but will be vastly under-estimated because most references to mental health issues are subsumed under the crimerelated activity that is being reported. Thus, there was no existing pre-BMHS implementation data meaning that the analysis for the current study focused on changes in successive years the BMHS was used.

During the study period extending from January 18, 2018 to December 31,2020, there were a total of 6,727 BMHS assessments (calls for service) completed by Guelph police officers (see Table 1). The total number of calls for service identified as being related to mental health increased by $28.1 \%$ over the study period from 1,898 in 2018 to 2,425 in 2020 . A total of $1,280(19.0 \%)$ involved a trip to the ED while $5,447(81 \%)$ did not result in an ED referral. Referrals to the ED decreased $31.2 \%$ from $481(25.4 \%)$ in 2018 to $331(13.6 \%)$ in 2020 while the number of incidents where there were no ED referrals increased by $48.3 \%$ from $1,412(74.6 \%)$ in 2018 to 2,094 (76.4\%) in 2020.

Police officer referrals to the ED were further subdivided into voluntary and involuntary. Voluntary referrals to the ED involved situations where the PSMD voluntarily agreed to accompany the police officer to the ED whereas involuntary referrals were those where a police officers used their legislative authority to apprehend and transport a PSMD to the ED for the purposes of a psychiatric examination. For the 3-year period of the study, of those persons taken to the ED, $868(67.8 \%)$ were involuntary referrals or apprehensions and 412 (32.2\%) voluntarily agreed to accompany police officers to the ED (see Table 2). Involuntary referrals decreased by $30.1 \%$ from 326 in 2018 , to 228 in 2020, and voluntary referrals decreased by $33.5 \%$ from 155 in 2018 to 103 in 2020.
TABLE 3 | Average call times (minutes): Involuntary referrals vs. No referral.

\begin{tabular}{lccc}
\hline Action & $\mathbf{2 0 1 8}$ (SD) & $\mathbf{2 0 1 9}$ (SD) & $\mathbf{2 0 2 0}$ (SD) \\
\hline Involuntary ED referral & $123(72.1)$ & $110(55.9)$ & $113(51.9)$ \\
No ED referral & $80(81.4)$ & $79(72.6)$ & $82(70.5)$
\end{tabular}

TABLE 4 | Average time (minutes) and cost per call: Involuntary referral vs. No ED referral.

\begin{tabular}{lcc}
\hline Action & $\begin{array}{c}\text { Average time/call } \\
\text { (minutes) (SD) }\end{array}$ & Average cost/call (SD) \\
\hline Involuntary ED referral $N=868$ & $116(61.4)$ & $\$ 215(\$ 165)$ \\
No ED referral $N=5,447$ & $81(74.1)$ & $\$ 134(\$ 155)$ \\
Difference & $35(96)$ & $\$ 81(\$ 226)$ \\
\hline
\end{tabular}

TABLE 5 | Average hospital ED Wait Times (minutes): Voluntary vs. involuntary referrals.

\begin{tabular}{lccc}
\hline Action & $\mathbf{2 0 1 8}$ & $\mathbf{2 0 1 9}$ & $\mathbf{2 0 2 0}$ \\
\hline Involuntary ED referral & $61(52.0)$ & $50(48.7)$ & $42(24.4)$ \\
Voluntary ED referral & $41(40.7)$ & $33(24.8)$ & $27(22.5)$ \\
Total ED referrals & $54(49.5)$ & $45(43.2)$ & $37(24.8)$ \\
\hline
\end{tabular}

When comparing the average time police officers devoted to involuntary referrals to the ED compared to no referrals to the $\mathrm{ED}$, the time spent on involuntary referrals decreased from $123 \mathrm{~min}$ in 2018 to $113 \mathrm{~min}$ in 2020 (see Table 3). There was a very slight increase in time devoted to calls where there was no trip to the ED from $80 \mathrm{~min}$ in 2018 to $82 \mathrm{~min}$ in 2020 . As to the time police officers were required to remain in the ED, the average wait time for voluntary referrals dropped from $41 \mathrm{~min}$ in 2018 to $27 \mathrm{~min}$ in 2020, while involuntary referrals also saw a drop from $61 \mathrm{~min}$ in 2018 to $42 \mathrm{~min}$ in 2020.

To calculate the cost of calls for service identified as being related to mental health, service calls were broken down into minutes and multiplied by the number of attending police officers and then multiplied by the salary of a first class constable which was $\$ 54.24 / \mathrm{h}$ or $\$ 0.90 / \mathrm{min}$. Thus, the average time per call for an involuntary referral was $116 \mathrm{~min}$ factoring in the number of police officers at 2.6 involved which cost on average \$215 per call compared to an average of $81 \mathrm{~min}$ where no hospital referral was involved which cost an average of $\$ 134$ per call. Thus, the difference between involuntary referrals to the ED and No ED referrals was an average of $35 \mathrm{~min}$ at an average of $\$ 81$ per call (see Table 4). In regard to the time police officers had to remain 
in the hospital, there was a decrease in time (minutes) over the study period for both involuntary and voluntary referrals. For involuntary referrals, police officers waited $42 \mathrm{~min}$ in the ED in 2020 down from $61 \mathrm{~min}$ in 2018 and for voluntary referrals $27 \mathrm{~min}$ in 2020 from $41 \mathrm{~min}$ in 2018 (see Table 5).

\section{DISCUSSION}

The purpose of the current study was to evaluate the costs and cost efficiency of the police response to calls for service identified as being related to mental health using the BMHS. The number of such calls for service increased by almost $30 \%$ over the study period which could be explained by the fact that police officers were increasingly more aware of indicators of mental health problems and in completing the BMHS. As to ED referrals, fewer persons were taken to the ED over the study period with an overall decrease of just over $30 \%$ and a decrease of $30 \%$ for involuntary referrals which may be due to officers having a more informed understanding of when to apprehend PSMDs. In other words, with the use of the BMHS, the police are now better able to determine when an ED visit is needed and when it is not needed. Also, further analysis would be needed to determine is the lower number of referrals to the $\mathrm{ED}$ is related to increased activity of the CRT which commenced activity in 2015.

An unfortunate limitation of the current study is the lack of baseline pre-implementation data that results from the fact that police services generally do not collect non-crime related data. Therefore, only decreases in ED referrals over time after implementation of the BMHS could be assessed. Because the largest decreases in ED referrals are likely to take place immediately after implementation of the BMHS, this study likely greatly understates the actual cost savings achieved by implementing the BMHS. Even so, this study still demonstrated significant reductions in ED referrals. The lower number of ED referrals may be related to the fact that identification practices may have changed over the period of observation that in turn led to fewer ED referrals and lowered costs. That is, with the implementation of the BMHS, police officers were required to complete the BMHS on all persons exhibiting indicators of mental health issues, some serious and some not as serious. The increase mental health calls could be the result of an increase in the number of BMHS assessments completed on persons exhibiting less serious indicators who in the past would have been ignored by police officers. With an increase in cases (or BMHS assessments being completed), the percentage of persons taken to the ED would naturally decrease with a corresponding decrease in associated costs. However, this assumes that increases in identification occurred from the first year of implementation of the BMHS onward, as increased identification from pre-BMHS to the first year of implementation cannot be assessed because pre-BMHS data on MH visits is not available.

Another limitation was the inability to determine from the data the proportion of persons taken to the ED who were subsequently admitted into psychiatric care. A higher proportion of admissions could support the argument that the BMHS enables police officers to identify the most appropriate persons to be taken to the ED which should result in a decrease in overall time officers are involved in ED referrals and less time spent in the ED, both of which should lead to cost-savings. Finally, a more general limitation of the study is the lack of a control group which would may have identified other factors influencing the results such as changes within the police service, community, or world (e.g., COVID-19) could have impacted or caused the findings.

An additional benefit of using the BMHS, is its ability to collect such statistics that police leaders can use to justify their budgets. This is the first study that examined specific costs associated with the use of a novel strategy to improve the police response to calls for service identified as being related to mental health. This analysis of the costs savings associated with the use of the BMHS helps to demonstrate that implementing the BMHS is a worthwhile investment for police services As was noted in a recent study involving the BMHS, the successful implementation of any form of new technology is problematic, and requires training and familiarity with the instrument (43). However, the BMHS shows great promise in predicting which calls evidence potentially serious mental health issues, and may require admission at the ED. As more and more police services in Canada and now the US implement the BMHS, and as the instrument continues to be developed and refined, it is anticipated that police officers, hospitals and community agencies will become increasingly familiar and comfortable in using the BMHS to support decision making, with the goal of improving outcomes. Although this analysis demonstrates that cost savings are achieved with continued use of the BMHS, the actual cost savings accrued from implementation of the BMHS are undoubtedly larger. Future studies should attempt to devise some method of collecting pre-implementation data so that the true cost savings of using the BMHS can be calculated. Police services could also consider the use of the BMHS in conjunction with the other models discussed in this paper as it may be possible to more accurately evaluate their effectiveness and costeffectiveness with more accurate data pertaining to the number of calls for service related to mental health.

\section{DATA AVAILABILITY STATEMENT}

The datasets presented in this article are not readily available because the dataset analyzed for this study can be found in the Canadian repository for interRAI Canada at the University of Waterloo, Waterloo, Ontario, Canada. Only interRAI Fellows have access to the data. Requests to access the datasets should be directed to https://uwaterloo.ca/interrai-canada/.

\section{ETHICS STATEMENT}

The studies involving human participants were reviewed and approved by Nipissing University Research Ethics Board. Written informed consent for participation was not required for this study in accordance with the national legislation and the institutional requirements. 


\section{AUTHOR CONTRIBUTIONS}

$\mathrm{RH}$ coordinated the project and wrote the draft of the manuscript and along with GB formulated the research questions. $\mathrm{JH}$

\section{REFERENCES}

1. Lamb HR, Weinberger LE, DeCuir WJ, Jr. The police and mental health. Psychiatr Serv. (2002) 53:1266-71. doi: 10.1176/appi.ps.53.10.1266

2. Morrissey JP, Fagan JA, Cocozza JJ. New models of collaboration between criminal justice and mental health systems. Am J Psychiatr. (2009) 166:12114. doi: 10.1176/appi.ajp.2009.09050670

3. Coleman TG, Cotton D. Police Interactions With Persons With a Mental Illness: Police Learning in the Environment of Contemporary Policing. Calgary: Prepared for the Mental Health and the Law Advisory Committee, Mental Health Commission of Canada (2012).

4. Coleman T, Cotton D. TEMPO: a contemporary model for police education and training about mental illness. Int J Law Psychiatry. (2014) 37:32533. doi: $10.1016 /$ j.ijlp.2014.02.002

5. Krameddine YI, Silverstone PH. How to improve interactions between police and the mentally ill. Front Psychiatry. (2015) 5:186. doi: 10.3389/fpsyt.2014.00186

6. Cotton D. The attitudes of Canadian police officers toward the mentally ill. Int J Law Psychiatry. (2004) 27:135-46. doi: 10.1016/j.ijlp.2004.01.004

7. Carey SJ. Police officers' knowledge of, and attitudes towards, mental illness in southwest Scotland. Scott Med J. (2001) 46:41-2. doi: 10.1177/003693300104600205

8. Cummings I, Jones S. Blue remembered skills: mental health awareness training for police officers. J Adult Protect. (2010) 12:14-9. doi: 10.5042/jap.2010.0410

9. Heslin M, Callaghan L, Barrett B, Lea S, Eick S, Morgan J, et al. Costs of the police service and mental healthcare pathways experienced by individuals with enduring mental health needs. Br J Psychiatry. (2017) 210:157-64. doi: 10.1192/bjp.bp.114.159129

10. Leuprecht C. The Blue Line or the Bottom Line of Police Services in Canada? Arresting Runaway Growth in Costs. Ottawa, ON: MacdonaldLaurier Institute (2014). p. 40.

11. Malm A, Pollard N, Brantingham P, Tinsley P, Plecas D, Brantingham P, et al. A 30 Year Analysis of Police Service Delivery and Costing. Abbotsford, BC: International Centre for Urban Research Studies (ICURS) (2005).

12. McCann, K. Policing and the Mentally Ill: A Review of Issues Related to Mental Health Apprehensions by Police in British Columbia. Vancouver, BC: International Centre for Criminal Law Reform and Criminal Justice Policy (2013).

13. Vaughan AD, Andresen MA. The cost of mental health-related calls on police service: evidence from British Columbia. In: Mitchell R, Huey L, editors. Evidence-Based Policing: An Introduction. Chicago, IL: Policy Press; The University of Chicago Press (2018). p. 173-85.

14. Charette Y, Crocker AG, Billette I. Police encounters involving citizens with mental illness: use of resources and outcomes. Psychiatr Serv. (2014) 65:5116. doi: 10.1176/appi.ps.201300053

15. Huey L, Andersen J, Bennell C, Campbell MA, Koziarski J, Vaughan AD. Caught in the Currents: Evaluating the Evidence for Common Downstream Police Response Interventions in Calls Involving Persons with Mental Illness. Royal Society of Canada (2021).

16. Koziarski J, O'Connor C, Frederick T. Policing mental health: the composition and perceived challenges of co-response teams and crisis intervention teams in the Canadian context. Police Pract Res. (2021) 22:97795. doi: 10.1080/15614263.2020.1786689

17. Compton MT, Bahora M, Watson AC, Oliva JR. A comprehensive review of extant research on crisis intervention team (CIT) programs. J Am Acad Psychiatry Law Online. (2008) 36:47-55.

18. Watson AC, Compton MT, Draine JN. The crisis intervention team (CIT) model: an evidence-based policing practice? Behav Sci Law. (2017) 35:43141. doi: 10.1002/bsl.2304 and $\mathrm{HK}$ were responsible for the data analysis, creating the charts and tables, and assisting in framing the research questions. All authors approved the submitted version of the work.

19. Horspool K, Drabble SJ, O'Cathain A. Implementing street triage: a qualitative study of collaboration between police and mental health services. BMC Psychiatry. (2016) 16:1-11. doi: 10.1186/s12888-016-1026-z

20. Lamanna D, Shapiro GK, Kirst M, Matheson FI, Nakhost A, Stergiopoulos V. Co-responding police-mental health programmes: Service user experiences and outcomes in a large urban centre. Int J Mental Health Nurs. (2018) 27:891-900. doi: 10.1111/inm.12384

21. Kane E, Evans E, Shokraneh F. Effectiveness of current policing-related mental health interventions in England and Wales and Crisis Intervention Teams as a future potential model: a systematic review. Syst Rev. (2017) 6:1-7. doi: 10.1186/s13643-017-0478-7

22. Puntis S, Perfect D, Kirubarajan A, Bolton S, Davies F, Hayes A, et al. A systematic review of co-responder models of police mental health "street" triage. BMC Psychiatry. (2018) 18:1-11. doi: 10.1186/s12888-018-1836-2

23. Kirst M, Francombe Pridham K, Narrandes R, Matheson F, Young L, Niedra $\mathrm{K}$, et al. Examining implementation of mobile, police-mental health crisis intervention teams in a large urban center. J Mental Health. (2015) 24:36974. doi: 10.3109/09638237.2015.1036970

24. Bhayani G, Thompson SK. SMART on social problems: lessons learned from a Canadian risk-based collaborative intervention model. Policing. (2017) 11:168-84.

25. Babayan A, Landry-Thompson T, Stevens A. Evaluation of the Brant Community Response Team Initiative: Six-Month Report. Brantford, ON: Brant County Health Unit (2015).

26. Russell HC, Taylor NE. Gaining Momentum: Multi-Sector Community Safety and Well-Being in Ontario. Ottawa, ON: Ontario Working Group on Collaborative, Risk-driven Community Safety, Ontario Association of Chiefs of Police (2016).

27. Corley C, Teare G. The Hub model: It's time for an independent summative evaluation. J Commun Saf Well-Being. (2019) 4:10-2. doi: 10.35502/jcswb.93

28. Rogers MS, McNiel DE, Binder RL. Effectiveness of police crisis intervention training programs. J Am Acad Psychiatry Law. (2019) 47. doi: 10.29158/JAAPL.003863-19

29. El-Mallakh PL, Kiran K, El-Mallakh RS. Costs and savings associated with implementation of a police crisis intervention team. Southern Med J. (2014) 107:391-5. doi: 10.14423/01.SMJ.0000450721.14787.7d

30. Watson AC, Compton MT. What research on crisis intervention teams tells us and what we need to ask. J Am Acad Psychiatry Law. (2019) 47:4226. doi: 10.29158/JAAPL.003894-19

31. Scott RL. Evaluation of a mobile crisis program: effectiveness, efficiency, and consumer satisfaction. Psychiatr Serv. (2000) 51:1153-6. doi: 10.1176/appi.ps.51.9.1153

32. Semple T, Tomlin M, Bennell C, Jenkins B. An evaluation of a community-based mobile crisis intervention team in a small Canadian police service. Commun Mental Health Journal. (2021) 57:567-78. doi: 10.1007/s10597-020-00683-8

33. Shapiro GK, Cusi A, Kirst M, O'Campo P, Nakhost A, Stergiopoulos V. Co-responding police-mental health programs: a review. Admin Policy Ment Health Ment Health Serv Res. (2015) 42:606-20. doi: 10.1007/s10488-014-0594-9

34. Cowell AJ, Broner N, Dupont R. The cost-effectiveness of criminal justice diversion programs for people with serious mental illness co-occurring with substance abuse: four case studies. J Contemp Crim Justice. (2004) 20:292314. doi: $10.1177 / 1043986204266892$

35. Schucan Bird K, Shemilt I. The crime, mental health, and economic impacts of prearrest diversion of people with mental health problems: a systematic review. Crim Behav Ment Health. (2019) 29:142-56. doi: 10.1002/ cbm. 2112

36. Seo C, Kim B, Kruis NE. Variation across police response models for handling encounters with people with mental illnesses: a systematic review 
and meta-analysis. J Crim Justice. (2020) 13:101752. doi: 10.1016/j.jcrimjus.20 20.101752

37. Seo C, Kim B, Kruis NE. A meta-analysis of police response models for handling people with mental illnesses: cross-country evidence on the effectiveness. Int Crim Justice Rev. (2021) 31:182-202. doi: 10.1177/1057567720 979184

38. Hoffman R, Hirdes J, Brown GP, Dubin JA, Barbaree H. The use of a brief mental health screener to enhance the ability of police officers to identify persons with serious mental disorders. Int J Law Psychiatry. (2016) 47:28-35. doi: 10.1016/j.ijlp.2016. 02.031

39. Hirdes J, Hoffman R, Brown GP, Barbaree H, Curtin-Telegdi N, Morris J, et al. interRAI Brief Mental Health Screener (BMHS) Assessment Forms and User's Manual: A Screening Level Assessment for Use by Police Officers and Other Front-line Service Providers (version 9.3) Washington DC: interRAI (2015).

40. Hirdes JP, van Everdingen C, Ferris J, Franco-Martin M, Fries BE, Heikkilä $J$, et al. The interRAI suite of mental health assessment instruments: an integrated system for the continuum of care. Front Psychiatry. (2020) 10:926. doi: 10.3389/fpsyt.201 9.00926

41. HealthIM. Available online at: https://healthim.com/ (accessed June 13, 2021).

42. Public Safety Canada. Government of Canada. Legal Analysis of Issues Pertaining to People with Mental Disorders in Contact with the Criminal
Justice System: Framework Overview. Available online at: https://www.crccccetp.gc.ca/en/archived-legal-analysis-issues-pertaining-people-mentaldisorders-contact-criminal-justice-system (accessed September 6, 2021).

43. Sanders CB, Lavoie J. Boundary objects and technological frames: officer's' perceptions and experiences using mental health screeners on the frontline. Policing Soc. (2020) 3:1-5. doi: 10.1080/10439463.2020.1813140

Conflict of Interest: The authors declare that the research was conducted in the absence of any commercial or financial relationships that could be construed as a potential conflict of interest.

Publisher's Note: All claims expressed in this article are solely those of the authors and do not necessarily represent those of their affiliated organizations, or those of the publisher, the editors and the reviewers. Any product that may be evaluated in this article, or claim that may be made by its manufacturer, is not guaranteed or endorsed by the publisher.

Copyright (C) 2021 Hoffman, Harman, Kinsell and Brown. This is an open-access article distributed under the terms of the Creative Commons Attribution License (CC BY). The use, distribution or reproduction in other forums is permitted, provided the original author(s) and the copyright owner(s) are credited and that the original publication in this journal is cited, in accordance with accepted academic practice. No use, distribution or reproduction is permitted which does not comply with these terms. 